\title{
Coastal Monitoring in the Context of Climate Change: Time-Series Efforts in Lebanon and Argentina
}

\begin{abstract}
By Abed El Rahman Hassoun*, Rodrigo Hernández-Moresino*, Elena S. Barbieri, Juan Cruz Carbajal, Augusto Crespi-Abril, Antonella De Cian, Lucía Epherra, Milad Fakhri, Abeer Ghanem, Houssein Jaber, Marie-Thérèse Kassab, Antonela Martelli, Anthony Ouba, Flavio Paparazzo, Juan Pablo Pisoni, Elie Tarek, and Juan Gabriel Vázquez (*equal first authors)
\end{abstract}

Since the beginning of the Industrial Revolution, anthropogenic activities have emitted greenhouse gases that are changing climate patterns worldwide, with exacerbated trends in some areas (MedECC, 2020). Climate change consequences are already detectable in many oceanic regions (e.g., warming, acidification, deoxygenation), and they are projected to intensify, affecting marine resources and the livelihoods of the millions of people who rely on them. Consequently, a well-equipped, multidisciplinary coastal ocean observing system is needed to monitor long-term patterns of the physical, chemical, and biological features in seawater where the most vulnerable communities and ecosystems coexist. The scientific understanding gained from such an observing system can be used to help managers and policymakers make informed decisions and tailor strategies and plans that would improve the resilience of coastal areas against climate change.

Here, we describe two coastal time-series stations, one located in the Mediterranean Sea and the other in the southwestern Atlantic Ocean, both in regions greatly impacted by climate change.

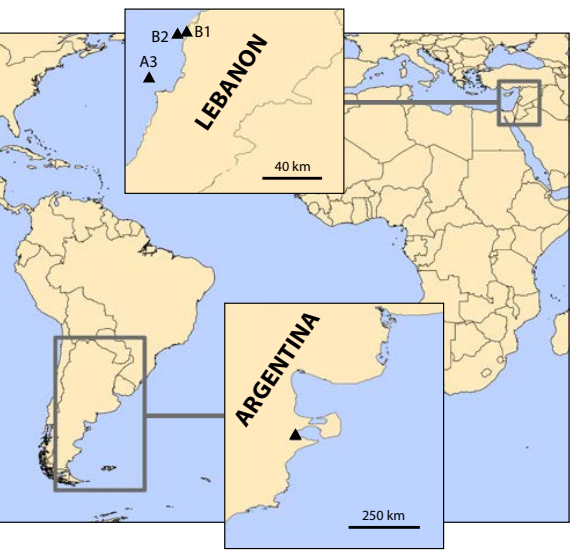

FIGURE 2. Variability of physico-chemical parameters measured monthly at station B2 off Lebanon in the Eastern Mediterranean Sea.

FIGURE 1. Locations of coastal time-series stations in the Eastern Mediterranean off Lebanon and in the southwestern Atlantic off Argentina.

\section{COASTAL MONITORING IN LEBANON}

Time-series stations in the Mediterranean Sea are still scarce and not equally distributed within its sub-basins, a significant obstacle in characterizing physical, chemical, and biological trends with good temporal and geographic coverage in a sea undergoing multiple changes due to climate change. We discuss two time-series stations located offshore Lebanon in the southeast Mediterranean Sea, an understudied area (Figure 1). Since 1999, stations B1 and B2, $5 \mathrm{~km}$ off the coast, have been sampled monthly in the upper $80 \mathrm{~m}$ for temperature, salinity, nitrates, nitrites, phosphates, plankton, and chlorophyll- $a$. Chemical variables added in 2012 include total alkalinity, total dissolved inorganic carbon, $\mathrm{pH}$, dissolved oxygen, and silicates. In addition, since 2012, research vessel CANA has sampled station $A 3$, located $10 \mathrm{~km}$ off the coast, seasonally for the parameters listed above down to $\sim 900 \mathrm{~m}$ depth.

Annual trends for the carbonate system for the period 2012-2017 demonstrate acidification in Lebanese waters $(-0.0021 \pm 0.001 \mathrm{pH}$ units per year in the upper $80 \mathrm{~m}$; Figure 2d; Hassoun et al., 2019). Further, annual variability in temperature since 1999 shows a warming trend of $0.09^{\circ} \mathrm{C}$ per year (Figure 2a; Ouba et al., 2016). Figure 2 also presents salinity and dissolved oxygen, although no distinct patterns are yet noted. At these stations, phytoplankton (microscopic marine algae) and zooplankton (microscopic marine organisms) populations and bottom- and water column-dwelling coccolithophores (a type of phytoplankton) are also sampled and are being studied to assess potential effects of climate change on the sea's tiniest creatures that would ultimately affect larger marine organisms, marine resources, and eventually coastal communities. 


\section{COASTAL MONITORING IN ARGENTINA}

At the same time and in a different hemisphere, another coastal monitoring effort is providing valuable climate change information. The Nuevo Gulf Oceanographic Station (Golfo Nuevo Estación Oceanográfica, GNEO), one of the first time-series oceanographic monitoring stations in Patagonia, Argentina, measures the temporal variability of physical, chemical, and biological processes in these waters. Sampling at Puerto Madryn's pier supports evaluation of seasonal and interannual variations in temperature, nutrients, and measured $\mathrm{pH}$ in the water column; the dynamics of the marine plankton community (chlorophyll- $a$ and phytoplankton and zooplankton identification); and the intensity and concentration of dust in the atmosphere. Temperature has been measured continuously since 2010 (Rivas et al., 2016), while measurement of other discrete variables began in 2018 when the GNEO was created. GNEO supplies data to the Argentine Marine Observatories Network (Red de Observación Marina Argentina, ROMA), the first national collaborative coastal physical and ecological time-series monitoring network, which collects measurements at several sites along the Argentine Sea and in Antarctic waters.

Preliminary results show wide annual temperature variability in Nuevo Gulf that is characteristic of temperate mid-latitude waters (Figure 3a). Chlorophyll-a presents a single peak of high concentration that is related to the austral spring phytoplankton bloom (Figure 3b). As the phytoplankton grow, nutrient concentration decreases in spring (Figure 3c). It will be possible to derive interannual variability and long-term trends for all parameters (temperature, chlorophyll, nutrients, and $\mathrm{pH}$, among others) as this time series grows longer. These variables may allow us to detect changes that reflect some alterations in the local environment. Carbonate system and dissolved oxygen trends, variables directly connected with the anthropogenic $\mathrm{CO}_{2}$ emissions, will also be assessed to help gauge the health of the gulf ecosystem.

\section{COMMON OPPORTUNITIES AND OBSTACLES: MONITORING FOR "THE OCEAN WE WANT"}

Participation in international networks enables scientific groups to address an important challenge of the UN Ocean Decade for Sustainable Development: to ensure a sustainable ocean observing system that delivers accessible, timely, and actionable data and information to all users. In this context, both time-series areas are part of the Global Ocean Acidification Observing Network (GOA-ON). In addition, these stations are also part of the NANO-DOAP network, a global study of coastal deoxygenation, ocean acidification, and productivity at selected sites.
ARGENTINA
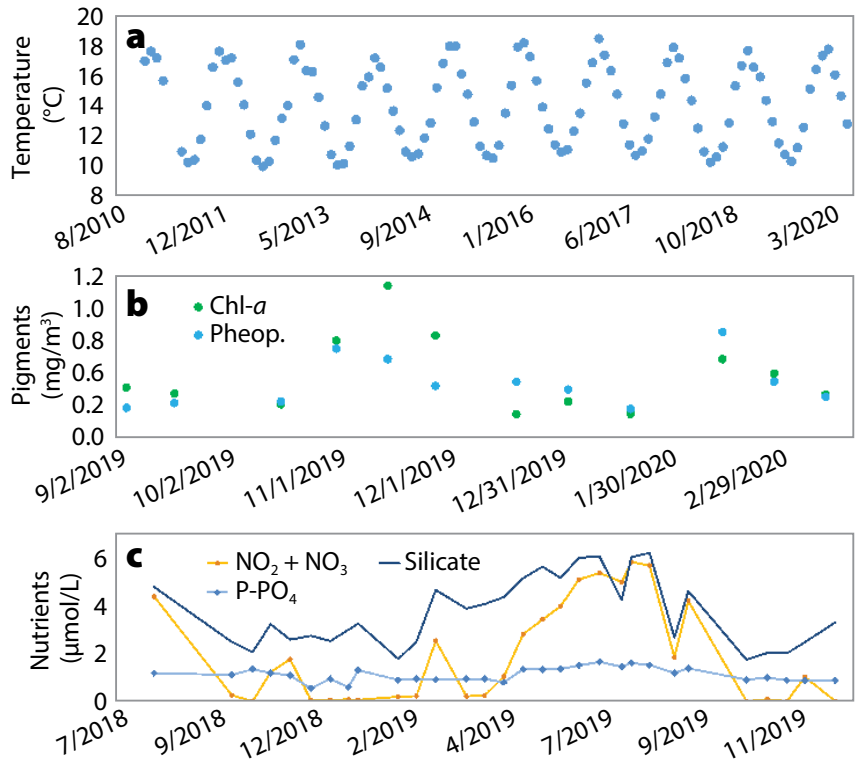

FIGURE 3. Variability of physico-chemical parameters measured monthly at Argentina's station in the southwestern Atlantic Ocean.

Monitoring stations are great platforms for promoting ocean literacy and public engagement. Associated training programs and capacity development activities offer opportunities for students to gain experience in an integrated, multidisciplinary oceanography field. We emphasize the importance of maintaining such coastal monitoring stations and increasing their numbers to gain more insights into how marine environments are coping in a changing ocean, particularly in coastal and marginal seas where global phenomena are exacerbated by local human activities. Timeseries studies are crucial to enabling society to understand current and future ocean conditions, to increasing community resilience to ocean hazards, and to promoting mitigation strategies that protect marine ecosystems. The main challenge is to maintain the frequency of these coastal monitoring stations to guarantee production of high-quality data compatible with GOA-ON's climatic data requirements and in line with UN Sustainable Development Goal 14.3.1 on ocean acidification data reporting.

\section{REFERENCES}

Hassoun, A.E.R., M. Fakhri, M. Abboud-Abi Saab, E. Gemayel, and E.H. De Carlo. 2019. The carbonate system of the eastern-most Mediterranean Sea, Levantine sub-basin: Variations and drivers. Deep Sea Research Part // 164:54-73, https://doi.org/10.1016/ j.dsr2.2019.03.008.

MedECC. 2020. Climate and Environmental Change in the Mediterranean Basin - Current Situation and Risks for the Future. First Mediterranean Assessment Report. W. Cramer, J. Guiot, and K. Marini, eds, Union for the Mediterranean, Marseille, France, $628 \mathrm{pp}$.

Ouba, A., M. Abboud-Abi Saab, and L. Stemmann. 2016. Temporal variability of zooplankton (2000-2013) in the Levantine Sea: Significant changes associated to the 2005-2010 EMT-like event? PLoS ONE 11(7):e0158484, https://doi.org/10.1371/journal.pone.0158484.

Rivas, A.L., J.P. Pisoni, and F.G. Dellatorre. 2016. Thermal response to the surface heat flux in a macrotidal coastal region (Nuevo Gulf, Argentina). Estuarine, Coastal and Shelf Science 176:117-123, https://doi.org/ 10.1016/j.ecss.2016.04.015.

ARTICLE DOI: https://doi.org/10.5670/oceanog.2021.supplement.02-05 


\section{AUTHORS}

Abed El Rahman Hassoun* (abedhassoun@cnrs.edu.lb), Milad Fakhri, Abeer Ghanem, Houssein Jaber, Marie-Thérèse Kassab, Anthony Ouba, and Elie Tarek, National Council for Scientific Research, National Center for Marine Sciences, Lebanon. Rodrigo Hernández-Moresino* (rodrigo@cenpatconicet.gob.ar), Elena S. Barbieri, Juan Cruz Carbajal, Augusto Crespi-Abril, Antonella De Cian, Lucía Epherra, Antonela Martelli, Flavio Paparazzo, Juan Pablo Pisoni, and Juan Gabriel Vázquez, Laboratorio de Oceanografía Biológica (LOBio), Centro para el Estudio de Sistemas Marinos (CESIMAR), Consejo Nacional de Investigaciones Científicas y Técnicas (CONICET), Argentina.

\section{ARTICLE CITATION}

Hassoun, A.E.R., R. Hernández-Moresino, E.S. Barbieri, J.C. Carbajal, A. Crespi-Abril, A. De Cian, L. Epherra, M. Fakhri, A. Ghanem, H. Jaber, M.-T. Kassab, A. Martelli, A. Ouba, F. Paparazzo, J.P. Pisoni, E. Tarek, and J.G. Vázquez. 2021. Coastal monitoring in the context of climate change: Time-series efforts in Lebanon and Argentina. Pp. 12-13 in Frontiers in Ocean Observing: Documenting Ecosystems, Understanding Environmental Changes, Forecasting Hazards. E.S. Kappel, S.K. Juniper, S. Seeyave, E. Smith, and M. Visbeck, eds, A Supplement to Oceanography 34(4), https://doi.org/ 10.5670/oceanog.2021. supplement.02-05.

\section{COPYRIGHT \& USAGE}

This is an open access article made available under the terms of the Creative Commons Attribution 4.0 International License (https://creativecommons.org/ licenses/by/4.0/), which permits use, sharing, adaptation, distribution, and reproduction in any medium or format as long as users cite the materials appropriately, provide a link to the Creative Commons license, and indicate the changes that were made to the original content. 